Western University Scholarship@Western

Electrical and Computer Engineering Publications Electrical and Computer Engineering Department

$1-2012$

\title{
Evaluating the Demand for Soft Skills in Software Development
}

Faheem Ahmed

Thompson RiverUniversity, famed@tru.ca

Luiz Fernando Capretz

University of Western Ontario, lcapretz@uwo.ca

Piers Campbell

United Arab Emirates University, p.campbell@uaeu.ac.ae

Follow this and additional works at: https://ir.lib.uwo.ca/electricalpub

Part of the Software Engineering Commons

Citation of this paper:

Ahmed, Faheem; Capretz, Luiz Fernando; and Campbell, Piers, "Evaluating the Demand for Soft Skills in Software Development" (2012). Electrical and Computer Engineering Publications. 152.

https://ir.lib.uwo.ca/electricalpub/152 


\section{FEATURE: IT WORKFORCE}

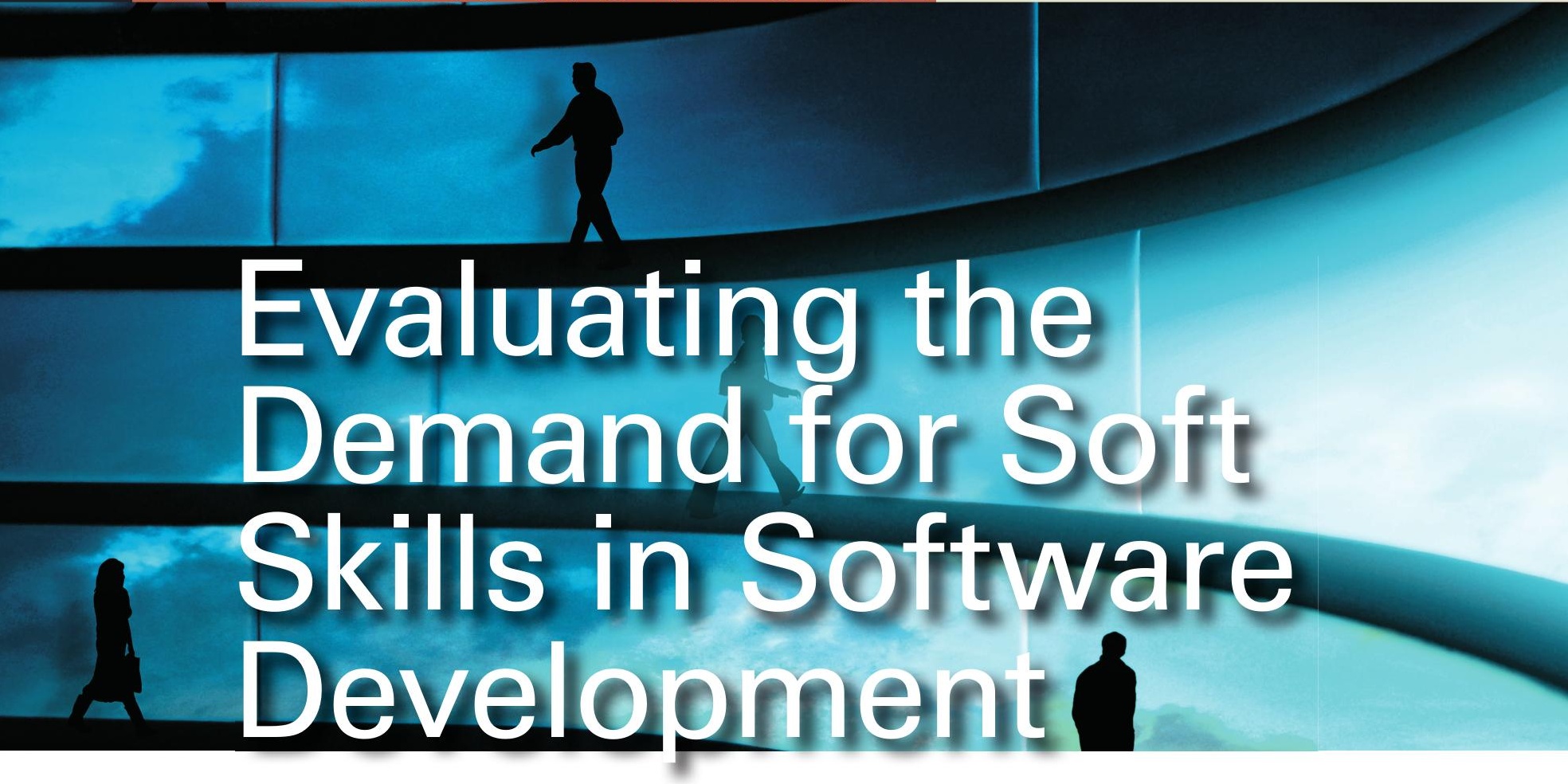

Faheem Ahmed, United Arab Emirates University

Luiz Fernando Capretz, University of Western Ontario, Canada

Piers Campbell, United Arab Emirates University

\section{An analysis of 500 advertisements for IT positions focuses on the soft skills mentioned in the ads, revealing which soft skills are in high demand for software development and which ones are neglected despite their importance.}

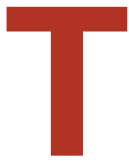
he production of any piece of software involves a human element, requiring activities such as problem solving, analytical thinking, communication, and cognitive reasoning. Furthermore, software development comprises different activities-system analysis, design, coding, and testing-which require not only different abilities but also different personality types. Managers and human resource professionals are thus increasingly using personality measures to evaluate the suitability of job applicants for various positions. ${ }^{1}$ According to Luis Martínez and his colleagues, personality is an important factor in team performanceassigning adequate roles to each team member can help lead to project success. ${ }^{2}$ (For more related research on soft skills, see the sidebar.)

Advertisements for software development jobs generally divide skill requirements into two categories: "hard" and "soft" skills. Hard skills are the technical requirements and knowledge an individual needs to carry out a task. Soft skills refer to the personality traits and attitudes that drive a person's behavior. ${ }^{3}$ Soft skills complement technical skills, ${ }^{4}$ so the ideal IT staff member should possess both. ${ }^{5}$ Software projects can achieve better results by assigning people with particular soft skills to different project phases.

Here, we analyze 500 advertisements for IT positions, focusing on the soft skills mentioned in the ads. Our analysis helps determine which soft skills are in high demand for software development jobs and which soft skills are neglected despite their importance.

\section{Survey Setup and Data}

We surveyed jobs advertised on the following online portals: workopolis.ca (North America), eurojobs.com (Europe), monsterindia.com (Asia), and seek.com.au (Australia). The geographical 


\section{Related Soft Skills Research}

S oft skills are usually overlooked in the software industry because the relationship between software development and soft skills is extremely complex to investigate. It takes a variety of soft and hard skills to solve the myriad of problems related to software development. ${ }^{1}$

We can broadly define the concept of professional abilities as the combination of knowledge, skills, and character that people possess in relation to their professional activity. ${ }^{2}$ Robert Feldt and his colleagues corroborate that empirical studies should collect psychometrics focusing on correlating personality and attitudes to software engineering processes and tools. ${ }^{3}$

According to Damien Joseph and his colleagues, there's a growing awareness that technical skills alone are insufficient for success in IT. ${ }^{4}$ Jen-Hur Wu and colleagues observe that understanding the importance of critical professional activities and the related skills and knowledge for each level of IT management might be critical in successful enterprise professional development. ${ }^{5}$ Also, Deborah Stevenson and Jo Ann Starkweather have investigated the human characteristics necessary to achieve success, identifying and rating preferred IT project management competencies across US industries. ${ }^{6}$

Note that soft skills are influenced by culture-for example, Judith Olson and Gary Olson report that the US and Netherlands rank individualism very high, whereas China, West Africa, and Indonesia are more collective in nature. ${ }^{7}$

\section{References}

1. L.F. Capretz and F. Ahmed, "Making Sense of Software Development and Personality Types," IT Professional, vol. 12 , no. 1, 2010, pp. 6-13.

2. A. Llorens-Garcia, X. Llinas-Audet, and F. Sabate, "Professional and Interpersonal Skills for ICT Specialists," IT Professional, vol. 11, no. 6, 2009, pp. 23-30.

3. R. Feldt et al., "Towards Individualized Software Engineering: Empirical Studies Should Collect Psychometrics," Proc. Int'I Workshop on Cooperative and Human Aspects of Software Engineering, ACM Press, 2008, pp. 49-52.

4. D. Joseph et al., "Practical Intelligence in IT: Assessing Soft Skills of IT Professionals," Comm. ACM, vol. 53, no. 2, 2010, pp. 149-154.

5. J. Wu, Y. Chen, and J. Chang, "Critical IS Professional Activities and Skills/Knowledge: A Perspective of IS Managers," Computers in Human Behavior, vol. 23, no. 6 , 2007, pp. 2945-2965.

6. D.H. Stevenson and J.A. Starkweather, "PM Critical Competency Index: IT Execs Prefer Soft Skills," Int'I I. Project Management, vol. 28, 2010, pp. 663-671.

7. J.S. Olson and G.M. Olson, "Culture Surprises in Remote Software Development Teams," ACM Queue, vol. 1, no. 9, 2003, pp. 52-59. distribution of the dataset is as follows: 31 percent from North America, 26 percent from Europe, 23 percent from Asia, and 20 percent from Australia. The dataset includes the following jobs distribution: system analyst (23 percent), software designer (21 percent), computer programmer (28 percent), and software tester (28 percent).

Only nine soft skills were identified in the advertisements:

- communication skills-the ability to convey information so that it's well received and understood;

- interpersonal skills - the ability to deal with other people through social communication and interactions under favorable and inauspicious conditions;

- analytical and problem-solving skills-the ability to understand, articulate, and solve complex problems and make sensible decisions based on available information;
- team player-someone who can work effectively in a team environment and contribute toward the desired goal;

- organizational skills-the ability to efficiently manage various tasks and to remain on schedule without wasting resources;

- fast learner-the ability to learn new concepts, methodologies, and technologies in a comparatively short timeframe;

- ability to work independently - can carry out tasks with minimal supervision;

- innovative - the ability to come up with new and creative solutions; and

- open and adaptable to change - the ability to accept and adapt to changes when carrying out a task without showing resistance.

We included an ad in our dataset if it listed at least one of these nine skills. We didn't keep a record of job advertisements that didn't specifically list any soft-skills requirements. 


\section{FEATURE: IT WORKFORCE}

Table 1. Summary of the survey results. High demand $(H)$ is greater than 66 percent, moderate demand $(M)$ is between 33 and 66 percent, and low demand $(\mathrm{L})$ is less than 33 percent.

\begin{tabular}{|c|c|c|c|c|c|c|c|c|c|c|c|c|}
\hline \multirow[b]{2}{*}{ Soft skills } & \multicolumn{3}{|c|}{$\begin{array}{l}\text { System } \\
\text { analyst }\end{array}$} & \multicolumn{3}{|c|}{$\begin{array}{l}\text { Software } \\
\text { designer }\end{array}$} & \multicolumn{3}{|c|}{$\begin{array}{l}\text { Computer } \\
\text { programmer }\end{array}$} & \multicolumn{3}{|c|}{$\begin{array}{c}\text { Software } \\
\text { tester }\end{array}$} \\
\hline & H & $\mathbf{M}$ & $\mathbf{L}$ & $\mathbf{H}$ & $\mathbf{M}$ & $\mathbf{L}$ & H & $\mathbf{M}$ & $\mathbf{L}$ & H & M & $\mathbf{L}$ \\
\hline Communication skills & $\sqrt{ }$ & & & $\sqrt{ }$ & & & $\sqrt{ }$ & & & $\sqrt{ }$ & & \\
\hline Interpersonal skills & & & $\sqrt{ }$ & $\sqrt{ }$ & & & & $\sqrt{ }$ & & & $\sqrt{ }$ & \\
\hline Analytical and problem-solving skills & $\sqrt{ }$ & & & & $\sqrt{ }$ & & & $\sqrt{ }$ & & & $\sqrt{ }$ & \\
\hline Team player & $\sqrt{ }$ & & & & $\sqrt{ }$ & & & $\sqrt{ }$ & & & & $\sqrt{ }$ \\
\hline Organizational skills & & $\sqrt{ }$ & & & & $\sqrt{ }$ & & $\sqrt{ }$ & & & $\sqrt{ }$ & \\
\hline Fast learner & & & $\sqrt{ }$ & & & $\sqrt{ }$ & & & $\sqrt{ }$ & & & $\sqrt{ }$ \\
\hline Ability to work independently & & & $\sqrt{ }$ & & & $\sqrt{ }$ & & $\sqrt{ }$ & & & & $\sqrt{ }$ \\
\hline Innovative & & & $\sqrt{ }$ & & & $\sqrt{ }$ & & & $\sqrt{ }$ & & & $\sqrt{ }$ \\
\hline Open and adaptable to changes & & & $\sqrt{ }$ & & & $\sqrt{ }$ & & & $\sqrt{ }$ & & & $\sqrt{ }$ \\
\hline
\end{tabular}

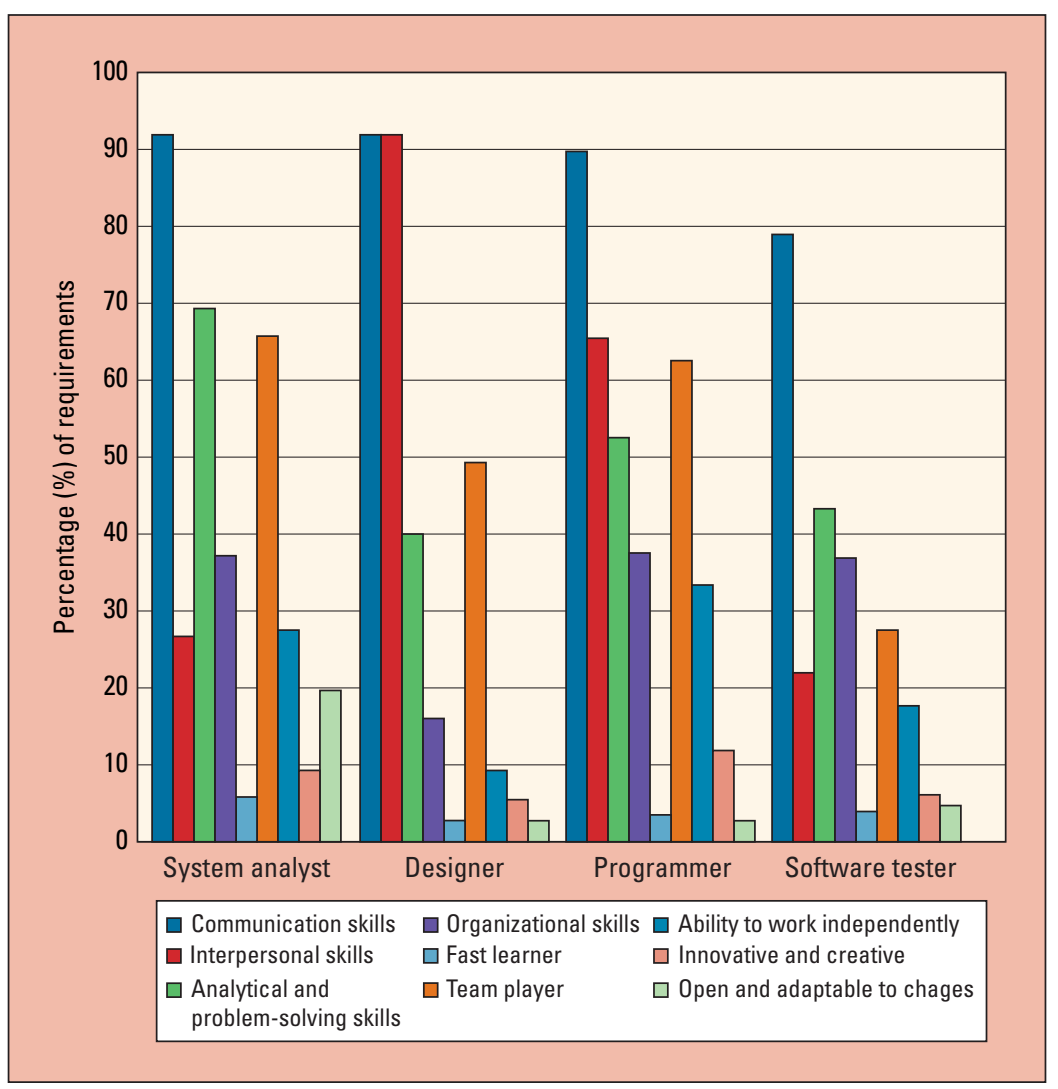

Figure 1. Soft skills requirements for various software development jobs.

\section{Survey Results}

Table 1 illustrates the survey's findings, providing an in-depth look at the current status of desirable soft skills in different software development roles. We used a three-point scale to represent the demand: high (greater than 66 percent), moderate (between 33 and 66 percent), or low (less than 33 percent).

\section{System Analyst}

System analysis requires a great deal of human interaction with users and clients, so strong communication skills are essential. Additionally, system analysts must be able to empathize with their customers to fully understand their needs, so interpersonal and analytical skills and the ability to be a team player should also be highly desirable. Yet Mark Misic and David Graf reported in a survey of skill requirements for system analysts that interpersonal skills were the least-valued skill (analytical skills were considered the most important, followed by technical and communication skills). ${ }^{6}$ Our review of 115 system analyst ads showed similar results (see Figure 1).

There was a high demand for communication skills (92 percent), analytical and problem-solving skills (69 percent), and team players (66 percent). There was moderate demand for organizational skills (37 percent). The least required soft skills were the following: independent worker (27 percent), interpersonal skills (26 percent), open and adaptable to change (20 percent), innovative and creative ( 9 percent), and fast learner (6 percent). Some of the vital soft skills are in high demand, but the software industry isn't paying enough attention to others, such as interpersonal skills and the ability to innovate. 
System analysts often interact with users, so the industry should better emphasize the need for such skills.

\section{Software Designer}

A good design usually yields better results, while a bad design can lead to disaster. Iterations aren't unusual in the designing process. Software designers should be able to see the big picture. They must perform a wide range of tasks, including prototyping processing functions, and defining inputs and outputs. These tasks require communication, interpersonal, and organizational skills.

According to Inger Boivie and colleagues, designers should have strong communication, interpersonal, analytical, and problem-solving skills, and they should be team players who are open to change. ${ }^{7}$ Our analysis of 105 software designer ads showed a high demand for communication (92 percent) and interpersonal (92 percent) skills. There was moderate demand for analytical and problem solving skills (40 percent) and for team players (49 percent). The least required skills were organizational (16 percent), independent worker ( 9 percent), innovative and creative (5 percent), fast learner ( 2 percent), and open and adaptable to changes (2 percent).

The industry should pay more attention to innovative and organizational skills, which are vital for software designers.

\section{Computer Programmer}

Translating the design into computer-executable code is the computer programmer's primary job. Programmers should attend to details, follow an open and logical process, and apply analytical thinking. Software programmers must translate a design into executable code, which requires understanding the design and making judgment calls. Programming tasks, such as determining the details of module logic, establishing file layouts, and coding programs, require little interpersonal contact; programmers have solitary work. However, they should be organized, fast learners, and able to adapt to changes. According to Gregory Sterling and Thomas Brinthaupt, a programmer should have communication, analytical and problem-solving, organizational, and interpersonal skills and should be creative. ${ }^{8}$

Our analysis of 140 computer programmer ads showed that the only soft skill in high demand was communication skills (90 percent). There was moderate demand for interpersonal skills (65 percent), team players (62 percent), analytical and problem-solving skills (52 percent), organizational skills (37 percent), and independent workers (34 percent). The ads weren't looking as much for computer programmers who are innovative and creative (12 percent), fast learners (3 percent), or open and adaptable to changes (2 percent).

\section{Software Tester}

Software testing involves identifying defects in a program and thus requires analytical and problemsolving skills. Software testers are viewed as the software development team's worst enemy, because they leave no stones unturned and bring news of defects. This requires good communication and interpersonal skills to keep the team active and avoid conflicts. ${ }^{9}$ According to Ilene Burnstein, communication, analytical, and problemsolving skills are important for software testers. Burnstein also says testers should be team players who are open to change and creative. ${ }^{10}$

Again, our analysis of 140 software tester ads showed that communication was the only soft skill in high demand (79 percent). There was moderate demand for analytical and problem-solving (43 percent) and organizational (37 percent) skills. The least required soft skills for software testers were team players ( 27 percent), interpersonal skills (22 percent), independent workers (17 percent), innovative and creative workers (6 percent), those open to change (5 percent), and fast learners (4 percent). The analysis revealed that the software industry isn't paying much attention to important soft skills for software testers.

\section{Regional Comparison}

Figure 2 shows a regional comparison of softskill requirements for the various IT jobs. Communication is the only soft skill in high demand across all four regions and job titles. Innovative and creative fast learners who can adapt to change are in low demand across all four regions and in all but one position. System analyst ads in North America exhibit a moderate demand for those who can adapt to change. Also in North America, the ads for computer programmers and system analysts showed a moderate demand for independent workers; other regions and job titles exhibited a low demand for this characteristic. 


\section{FEATURE: IT WORKFORCE}

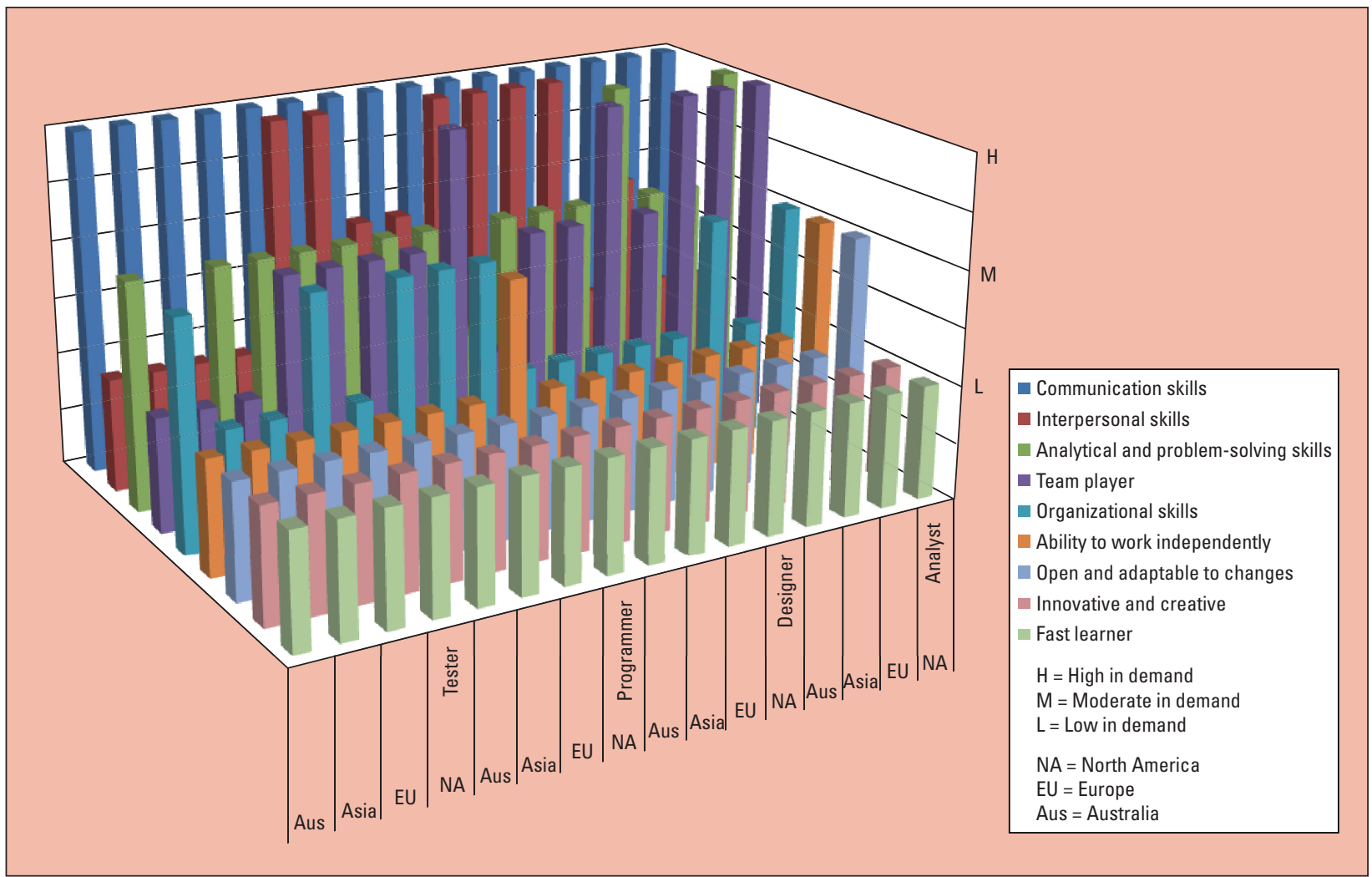

Figure 2. A regional comparison of soft-skill requirements. Communication is the only soft skill in high demand across all regions and job titles.

In the Australian market, organizational skills are in low demand for computer programmers, but the remaining three regions exhibit moderate needs in this area. Australia also showed a lesser need for team players for the system analyst position, exhibiting only a moderate demand, whereas the other regions showed a high demand for team players for this position. However, team players are in low demand for the software tester position in the Australian, Asian, and European job markets.

Analytical and problem-solving skills are in high demand for system analysts in both North America and Australia. The remaining regions exhibit only moderate demand for this skill. All four regions had a high demand for interpersonal skills. Conversely, the skill is in low demand for software testers in each of the four regions.

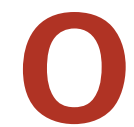
ur survey indicates that soft skills are in demand in the software industry, but only to a limited extent. This highlights the lack of understanding of the role that soft skills play in an employee's professional ability and performance. For example, analytical and problem-solving skills are in high demand for systems analysts but are in only moderate demand for other roles, despite the fact that software development is fundamentally a problem-solving profession. Also, innovative, fast learners who can adapt to change are in low demand, which is disconcerting because the software field changes rapidly, as do customer requirements and expectations. Furthermore, only the software designer ads showed a high demand for interpersonal skills, even though system analysts and software testers also require this skill.

Organizations would be well served by diversifying the soft skills of their software developers. This would provide richer talent and viewpoints to help them tackle the inherent complexity of software construction.

\section{References}

1. M.G. Rothstein and R.D. Goffin, "The Use of Personality Measures in Personnel Selection: What Does Current Research Support?" Human Resource Management Rev., vol. 16, no. 2, 2006, pp. 155-180.

2. L. G. Martínez et al., “Big Five Patterns for Software Engineering Roles Using an ANFIS Learning Approach with RAMSET," Advances in Soft Computing, 
Lecture Notes in Computer Science, vol. 6438, 2010, pp. 428-439; DOI:10.1007/978-3-642-16773-7_37.

3. A. Roan and G. Whitehouse, "Women, Information Technology and Waves of Optimism: Australian Evidence on Mixed-Skill Jobs," New Technology, Work and Employment, vol. 22, no. 1, 2007, pp. 21-33.

4. T.L. Lewis et al., "Are Technical and Soft Skills Required?" Proc. 4th Workshop on Computing Education Research, ACM Press, 2008, pp. 91-100.

5. W. Chou, "Smart Staff Recruiting," IT Professional, vol. 11, no. 2, 2009, pp. 57-59.

6. M.M. Misic and D.K. Graf, "Systems Analyst Activities and Skills in the New Millennium," J. Systems and Software, vol. 71, nos. 1-2, 2004, pp. 31-36.

7. I. Boivie, J. Gulliksen, and B. Göransson, "The Lonesome Cowboy: A Study of the Usability Designer Role in Systems Development," Interacting with Computers, vol. 18, no. 4, 2006, pp. 601-634.

8. G.D. Sterling and T.M. Brinthaupt, "Faculty and Industry Conceptions of Successful Computer Programmers," J. Information Systems Education, vol. 14, no. 4, 2004, pp. 417-424.

9. J.A. Whittaker, "What is Software Testing? And Why Is It So Hard?" IEEE Software, vol. 17, no. 1, 2000, pp. 70-79.

10. I. Burnstein, Practical Software Testing, Springer, 2003.
Faheem Ahmed is an assistant professor in the Faculty of Information Technology at the United Arab Emirates University. His research interests are software product lines, software process modeling, software process assessment, and empirical software engineering. Ahmed has a PhD in electrical engineering from the University of Western Ontario, Canada. He's a member of IEEE. Contact himatf.ahmed@uaeu.ac.ae.

Luiz Fernando Capretz is an associate professor and the assistant dean of IT and e-Education at the University of Western Ontario, Canada. His research interests include software engineering, human aspects of software engineering, software estimation, software product lines, and software engineering education. Capretz has a PhD in computing science from the University of Newcastle upon Tyne. He's a senior member of IEEE, a distinguished member of the ACM, an MBTI (Myers-Briggs Type Indicator) certified practitioner, and a Professional Engineer in Ontario,Canada.Contact him at lcapretz@uwo.ca.

Piers Campbell is an assistant professor in the Faculty of Information Technology at the United Arab Emirates University. His research interests include knowledge discovery and software ecosystems. Piers received his PhD from the Faculty of Engineering at the University of Ulster in the United Kingdom. He's a member of IEEE. Contact him at p.campbell@uaeu.ac.ae.

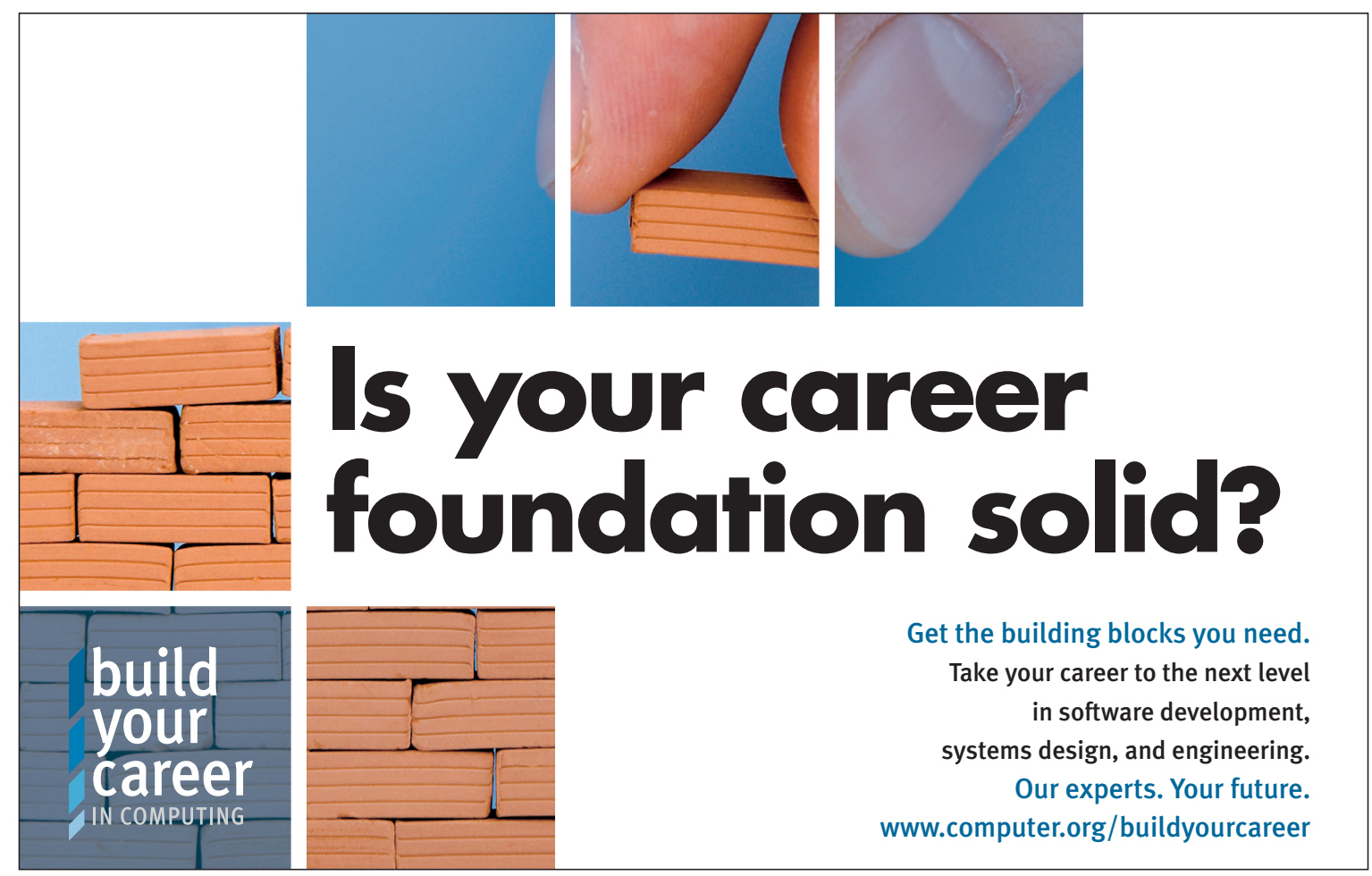

